\title{
Estigma territorial y gentrificación post desastre 2014. El caso de las poblaciones pericentrales norte de I quique
}

Post disaster territorial stigma and gentrification. The case of the inner city slums in the northern area of Iquique

Gricel Labbé, Pedro Palma, Vladimir Venegas, Felipe Ulloa

\section{Filiación}

CITé Observatorio

E mail: gmlabbe@uc.cl, calorio.p@hotmail.com, vnvenega@gmail.com, fel.ulloap@gmail.com

Primera versión recibida en: 05 de abril, 2016 Última versión recibida en: 06 de Junio, 2016

\section{Resumen}

La gentrificación en ciudades intermedias como Iquique, es un fenómeno incipiente. Sin embargo, la velocidad de esta dinámica ha llevado al capital inmobiliario y al gobierno local a mirar espacios históricos, devaluados debido al estigma territorial con el que cargan, así como al deterioro causado en los últimos desastres naturales, para emplazar nuevas ofertas inmobiliarias. Es por esto que el caso de las poblaciones pericentrales norte de Iquique ayuda a profundizar el estudio sobre la gentrificación en un escenario post desastre, donde los sujetos potencialmente desplazados son los habitantes más vulnerables de la ciudad. En dicho escenario, gentrificar el área post desastre representa una oportunidad para el gobierno local de hacer limpieza social, y a su vez permite a los agentes inmobiliarios capitalizar con los desastres. ${ }^{1}$

\section{Palabras claves}

Espacios de desinversión; limpieza social; desplazamiento.

\begin{abstract}
The process of gentrification in middle size cities like Iquique, is a growing phenomenon. The speed of this dynamic has made both real estate developers and local government to look at historic grounds, which have suffered a strong devaluation due to territorial stigma, along with the consequences of recent natural disasters, as a viable option to energize new real estate development. Thus, the case of north pericentral settlements of Iquique help to deepen the study about gentrification in a post-disaster scenario, where the subjects potentially displaced are the most vulnerable inhabitants of the city. Gentrification under said conditions represents an opportunity for the local government to do social cleanup, and allows the real-estate agencies to capitalize with disasters.
\end{abstract}

\section{Key words}

Territorial Stigma, Post-disaster gentrification, Social cleaning

1 El artículo devela parte de los resultados obtenidos en el Fondecyt de Iniciación 1112124 “Mercado de arriendo y trayectorias residenciales de los precarios urbanos en el área central de Santiago e Iquique"

Los autores agradecen a Catalina Aguilera, Licenciada en Antropología, por su apoyo en la redacción del

artículo. 


\section{Sumario}

Introducción

1 Iquique, desinversión en espacios centrales y pericentrales

2 Estigma territorial, hiperguetos y limpieza social: "el problema" de las poblaciones del pericentro norte de Iquique

3 Terremoto en el Norte Grande: ¿oportunidad frente a la escasez de suelo?

4 Discusión

5 Conclusión

Bibliografía

\section{I ntroducción}

La siguiente investigación indagó en las interrelaciones que se presentan en siete de las poblaciones pericentrales de la zona norte en la ciudad de Iquique (Jorge Inostrosa, Villa Progreso, Villa Quitasol, Carol Urzúa, Villa Navidad, San Carlos Ferronor), y la nueva oferta inmobiliaria para clases medias del sector, la cual está produciendo incipientes procesos de gentrificación (López, 2013; Inzulza y Galleguillos, 2014) (Fig. 1). Estas poblaciones desde su surgimiento en la década de 1970 se han constituido como espacios frontera, de desinversión e hiperguetos (Labbé, 2014). Sin embargo, después del terremoto en abril de 2014, este sector ha empezado un proceso de revalorización, debido al discurso de la escasez relativa de suelo impuesto por el sector privado y público (Pantoja, 2015) ${ }^{2}$, como también a la necesidad de dejar de construir en zonas de riesgos, lo cual ha llevado a una relocalización de la oferta inmobiliaria hacia zonas seguras, resultando en elevados precios de suelo en áreas que ni siquiera tienen factibilidad urbana. Este escenario ha sido aprovechado por el privado que ha visto en las poblaciones pericentrales norte de la comuna una posibilidad de inversión y desarrollo inmobiliario, ya que se emplazan en un sector seguro frente amenazas de tipo natural, conectado al centro de comercio y servicios, a sólo metros de la Zona Franca (principal empleador de la ciudad) y próximo a las zonas confort ${ }^{3}$ de la ciudad. Sin embargo, las poblaciones que ahí se localizan cuentan con un fuerte estigma territorial, asociado en primer lugar al origen de sus habitantes, mayoritariamente pampinos y ferroviarios empobrecidos, provenientes de las salitreras de Pozo Almonte en la década de 1970 y en el último tiempo inmigrantes latinoamericanos, específicamente afrodescendientes, que sumado a las patologías urbanas (violencia urbana y tráfico de drogas) (Wacquant, 2007) presentes en la zona, han permitido clasificar a estas poblaciones como hiperguetos (Labbé, 2014). Bajo este escenario y desde hace un par de años atrás, los desarrolladores inmobiliarios y el MINVU han comprado lotes y viviendas en las poblaciones (específicamente en la frontera de éstas), con el objetivo de generar proyectos inmobiliarios en altura, que han propiciado

2 Entrevista enmarcada en el Fondecyt 1112124, a Jorge Pantoja C. Presidente de la Red Social Iquique de la CCHC.

3 Las zonas confort, corresponden a las áreas de la ciudad con mayor valor de suelo, en la ciudad de I quique este sector es la franja costera, y en específico los sectores de Cavancha y Bajo Molle. 
la llegada de habitantes de clase media y media-alta, desplazando a los antiguos residentes de estas poblaciones hacia Alto Hospicio y a otras poblaciones del sector sur (Palma, 2014).

La hipótesis que conduce esta investigación reflexiona sobre la idea de que los desarrolladores inmobiliarios han aprovechado el estigma territorial que devalúa el precio del suelo en ciertas poblaciones para promover procesos de gentrificación, por la vía de introducir edificios en altura, fenómeno que se intensificó post catástrofe del 2014.

Coherentemente con la problemática precedente, el objetivo de la siguiente investigación es determinar si este proceso se intensificó post terremoto 2014 en las poblaciones estigmatizadas del pericentro norte de la ciudad de Iquique (Fig. 1), siendo la gentrificación entendida como una reconfiguración socio-espacial, donde se desplazan grupos de bajos ingresos de barrios centrales y pericentrales, pero no de manera homogénea (Contreras, 2012) y en donde el papel principal lo juegan las inmobiliarias y el gobierno local - por sobre una nueva clase media- tanto en la revalorización de zonas originalmente deterioradas, como en la ejecución de una pseudo renovación urbana en base a densificación en altura (López, 2013; Inzulza y Galleguillos, 2014).

Con respecto a la metodología utilizada, en primer lugar se analizó la evolución del valor del suelo y la oferta inmobiliaria en la ciudad de Iquique en seis períodos (1990- 19952000-2005-2010-2013) ${ }^{4}$, posteriormente y con la utilización de Censos 1992, 2002, $2012^{5}$ y catastros aplicados en terreno durante los años 2013, 2014 y 2015, se describieron las variaciones en el perfil socioeconómico del habitante histórico (antes del terremoto de abril 2014) y el nuevo habitante (post abril 2014) con el fin de debatir si se están llevando a cabo los fenómenos de gentrificación y limpieza social. Sumado a lo anterior, se catastró la evolución del uso de suelo en dos períodos (enero y agosto 2014) ${ }^{6}$, para conocer si hubo una variación en la oferta de servicios enfocados en estos nuevos habitantes de clase media.

El artículo consta de cinco apartados incluyendo discusión y conclusión, los cuales tienen relación con la evolución histórica urbana del área, enfatizando las dinámicas ocurridas durante los últimos veintiséis años, es decir, desde la década de 1990 a la fecha, considerando el año 2014, fecha del terremoto, como un punto de inflexión para el análisis. Frente a esto el primer apartado relata la evolución del valor del suelo y la oferta inmobiliaria versus el discurso de la escasez relativa de suelo. La segunda parte evidencia el fenómeno de la hiperguetización experimentado por las poblaciones nororientales de I quique que devalúa el precio del suelo. El tercer apartado vislumbra cómo espacios post desastre, son vistos por el inmobiliario como oportunidad para la inversión inmobiliaria. En el punto cuatro establece a modo de discusión cómo la gestión del gobierno local en procesos de gentrificación genera cierta limpieza social, debido a la inexistencia de políticas públicas que protejan y garanticen la permanencia de habitantes históricos en las poblaciones amenazadas por la oferta inmobiliaria. Para

4 Se consideraron estos periodos de tiempo debido a que el año 1990 era el dato más antiguo del que se tenía registro, y desde ahí en adelante se establecieron intervalos de 5 años para el estudio.

5 Se utilizará el Censo 2012 con actualización en terreno 2015 ya que uno de los principales problemas detectados es la inconsistencia de los datos en algunas comunas.

$6 \mathrm{El}$ período considerado para analizar la evolución de los usos de suelo busca atisbar los cambios ocurridos con la llegada de una nueva oferta inmobiliaria, por ende, no se utilizaron los mismos periodos antes descritos. 


\section{URBANISMO}

finalizar, el quinto apartado presenta la conclusión del trabajo, respondiendo la pregunta de investigación propuesta.
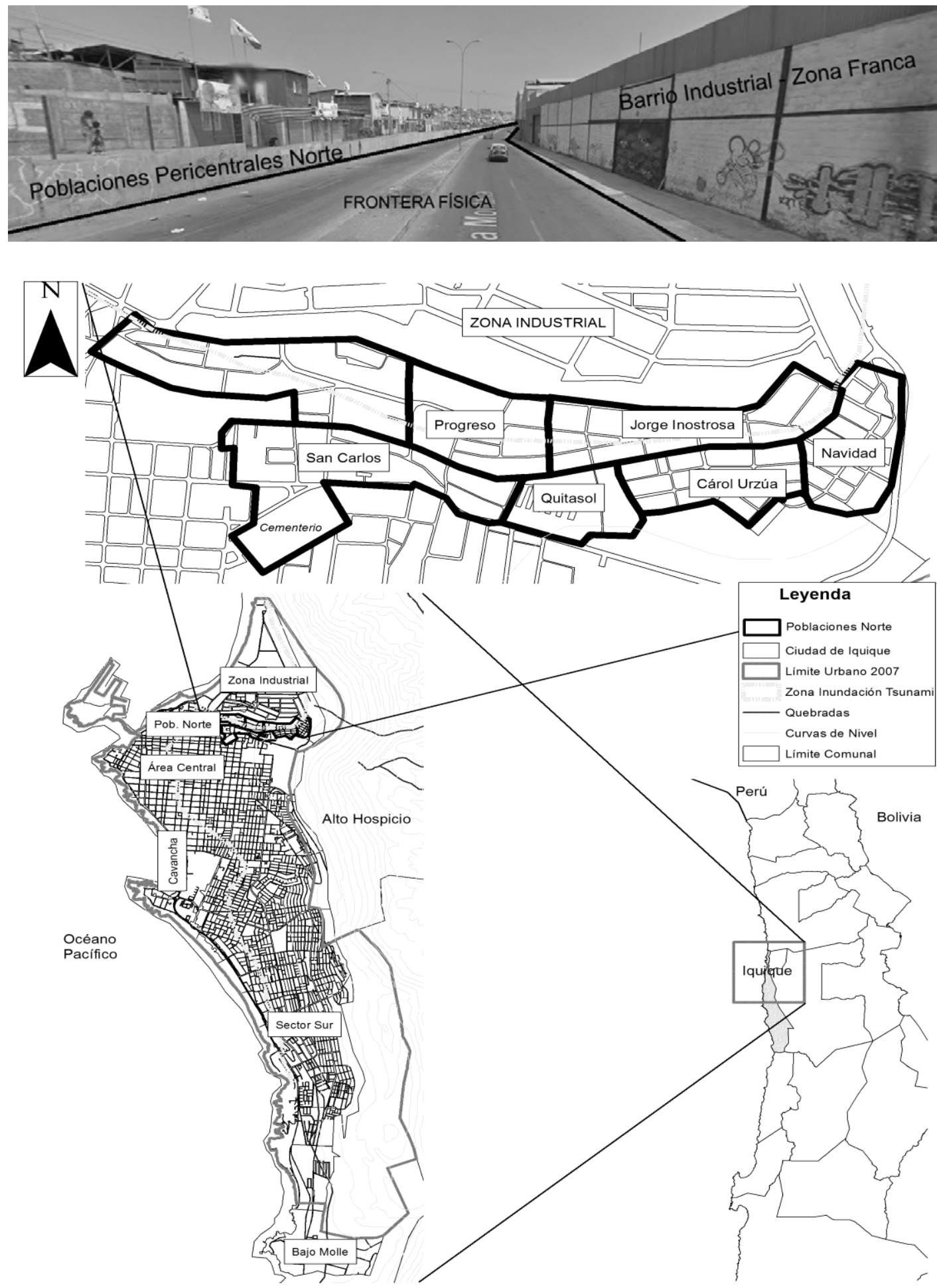

Fig. 1 Poblaciones pericentrales norte de la ciudad de I quique Fuente: Elaboración propia a partir de Fondecyt 1112124. 


\section{I quique, desinversión en espacios centrales y pericentrales}

I quique es una ciudad intermedia, con 184.953 habitantes en el año 2012 (Instituto Nacional de Estadísticas INE, 2012), y comuna capital de la Región de Tarapacá. Desde la década de 1990, el centro y pericentro de la ciudad han experimentado fenómenos complementarios en términos de movilidad, ya que, por un lado se produjo un éxodo de población hacia el extremo sur y zonas confort, un movimiento centrífugo de población que promovió la expansión urbana, por otro lado, esto provocó un deterioro en el casco fundacional, lo cual ha propiciado la llegada de migrantes latinoamericanos vulnerables como plantea Palma (2014). Sumado a esto, el arribo del capital inmobiliario plasmado en construcciones de primera y segunda residencia "destinados fundamentalmente al consumo de estratos medios (turistas, residentes permanentes o temporales, inversionistas, etc.)" (Lees, Slater y Wyly, 2008 en Delgadillo, 2010:41), proceso que es parte de un fenómeno de mayor extensión, pues "en algunas áreas céntricas de Santiago, Iquique, Antofagasta, Valparaíso, Talca y otras ciudades chilenas se han generado procesos de cambio socio espacial que puede describirse como de gentrificación generalizada" (Contreras, 2014: 14).

Adentrándonos en el discurso sobre la ciudad y las dinámicas consideradas, Iquique posee un crecimiento urbano limitado por su posición geográfica, ya que cuenta por un lado con el océano pacífico, por otro con un farellón costero que impide la expansión continua este a oeste, y por último una escaza planicie litoral donde se encuentra toda el área urbana consolidada, la cual está condicionada por la aridez, salinidad del suelo, geomorfología, movimientos sísmicos y riesgo frente a la amenaza de tsunamis.

"Según el Ministerio de Vivienda y Urbanismo el sistema urbano de Iquique, incluyendo Alto Hospicio al ser todavía comunas dependientes administrativamente, fue la tercera ciudad que más creció en superficie entre los años 1993 - 2003, mientras que la media nacional fue de aproximadamente $30 \%$, la zona que integra la capital de la región de Tarapacá creció casi un 70\%, llegando a las 2.600 ha aproximadamente" (Figueroa y Fuentes, 2009) ${ }^{7}$.

I quique como comuna autónoma, creció entre 1993 y el 2003 a razón de 277 ha anuales las cuales están en su mayoría contenidas sobre el límite del Plan Regulador Comunal (PRC) del 2007. Si bien es un crecimiento sostenido, éste no presenta una explosión sobre la mancha urbana, ya que para el 2011 siguió aumentando en 155 ha, esto indica que el gran crecimiento develado atañe a dinámicas expansivas ocurridas en Alto Hospicio, evidenciando una tendencia a la densificación frente a la expansión urbana en la urbe. Iquique creció a un ritmo de 33 ha anuales y Alto Hospicio lo hizo en 91 ha anuales. En otro aspecto, es importante recalcar que para el año 1993, la ciudad de I quique contaba con un centro consolidado y con 1.389 ha en total, con una leve tendencia a expandirse hacia el sector de Bajo Molle, con un tipo de crecimiento continuo superando el límite del PRC hacia el sur, pero no sobrepasando el área de este (2.136 ha). Para el año 2003 existe un relleno de la planta sur de la ciudad y un crecimiento del área Bajo Molle. Por último, hacia el 2011, existe una consolidación del casco urbano de la ciudad y la utilización de la planicie litoral en su totalidad. El límite

7 Cabe resaltar que esta información debería ser analizada con más detalle ahora que son dos comunas independientes. 
urbano es superado físicamente, pero no completamente, ya que éste se extiende sobre el farellón y la duna dragón hacia el sureste de la ciudad, impidiendo la extensión de la urbe. Ante las restricciones que establecen este crecimiento, la ciudad ha consolidado su desarrollo urbano por un lado hacia algunos terrenos disponibles del sur, donde "los ricos, se blindan en sus casas (...), bajo la fórmula del condominio" (Guerrero 2007:161), y por otro, ha visto en el borde costero -sobre el área de inundación frente a tsunamis- y en el área central, la oportunidad de concretar proyectos inmobiliarios, desplazando población de menos recursos con el fin de gentrificar (Delgadillo, 2010), fenómeno en desarrollo desde la década de 1990, en la península de Cavancha.

En este contexto, la expansión urbana hacia el sur ha generado crecimiento irregular sobre suelo rural enfatizando la dispersión urbana, mientras que por otro lado, la llegada de grupos medios hacia la zona litoral ha acentuado el desarrollo geográfico desigual con la concentración del capital sobre espacios que conviven con islas de pobreza (Harvey, 2004a). Estos tipos de urbanización no son producto del azar, sino que responden a zonificaciones concebidas en el PRC, como también a los planes seccionales ${ }^{8}$ complementarios, que disponen terrenos en el extremo más distante de la ciudad, debido a la localización en el sector norte de industrias portuarias e industriales las cuales generan externalidades ambientales negativas, propiciando la relocalización de familias en el sector sur, urbanizando el borde costero y dejando a merced del deterioro el centro y pericentro de la ciudad. Es por esto que el Ministerio de Obras Púbicas, MOP (2005: 11) plantea que el "área central ha experimentado una relevante pérdida de población, en específico distritos como; Parque Balmaceda, Puerto, Hospital, Caupolicán y Arturo Prat han disminuido su población en 11,4\% entre los años 1992 y 2002", concentrando estas tres últimas áreas hogares de bajos ingresos, y siendo actualmente espacios de acogida de inmigrantes latinoamericanos, debido a una oferta de vivienda más asequible. A su vez, el distrito Barrio Industrial, el que alberga las poblaciones nororientales de la ciudad, refleja incipientemente un fenómeno similar, con una tasa que tiende a ralentización, alcanzando para este sector una población de 12.791 habitantes. Es por esto que el centro se conforma como escenario de "vaciamiento, pérdida de población, deterioro, tugurización" (Contreras, 2012:27) y de frontera para la gentrificación (Smith, 1996) es decir, un espacio de desinversión donde el capital puede anclarse. De todas formas se requiere de un análisis más cuidadoso, ya que existe una fracción de población vulnerable que ve en el centro y pericentro una oportunidad de articular trabajo-residencia, lo cual ha generado que está área se convierta en un espacio receptor de habitantes de clase media y media baja, los que se localizan sobre espacios de desinversión, que otorgan un resguardo frente a las amenazas de carácter natural.

El discurso del gobierno local, el sector inmobiliario y el de la Cámara Chilena de la Construcción $(\mathrm{CCHC})$ es que Iquique ya no tiene espacio para crecer por la escasez de suelo urbano, lo que ha redundado en elevados costos de los terrenos para construir, teniendo aumentos de $10 \mathrm{uf} / \mathrm{m}^{2}$ en los sectores de menor valor de suelo (poblaciones pericentrales norte) y de $40 \mathrm{uf} / \mathrm{m}^{2}$ en los sectores más exclusivos (borde mar) en la última década.

8 El Plan Regulador Comunal data de 1981 y ha debido adaptarse con varios planes seccionales como respuesta a nuevos procesos de desarrollo urbano, entre ellos el "Plan Seccional Sur (1989), Plan Seccional Borde Costero (1993), el Plan Seccional Alto Hospicio/Alto Molle (2001) e incluso la actualización del PRC" (MOP, 2005; p. 9). 
Asociado a lo relatado en párrafos anteriores se logra divisar la nula existencia de regulación en el área central deteriorada, a la inversa de lo que ocurre sobre los espacios de inversión asociados al turismo y segunda residencia, con planes seccionales y zonas de renovación urbana. Es así como se logra constatar la importancia de los instrumentos de planificación territorial, el gobierno local y los inmobiliarios para la consolidación de frentes de inversión, que han generado una distribución inequitativa de los recursos en la ciudad. Se evidencian dos momentos urbanos que tienen relación con la consolidación de los frentes inmobiliarios y el desplazamiento de población. El primero ocurrió en la década de los años 90 al 2010, denominado como turistificación. El segundo, del 2010 hasta hoy en día, denominado por Lees, Slater y Wyly (2008) en Delgadillo (2010) como nuevo urbanismo colonizador o gentrificación post desastre.

\subsection{Turistificación sobre el área de inundación}

Desde mediados de la década de 1980 y principios de 1990, un boom inmobiliario se ha estado desarrollando en las ciudades del norte de Chile, destacando Iquique debido al auge asociado a la industria minera, la apertura de la zona franca (Guerrero, 2007) y la financiarización de la economía (De Mattos, 2014). Este proceso ha ido de la mano con la modificación de barrios históricos y el desplazamiento de población vulnerable de origen pampino, como también personas relacionadas con la industria de la pesca y el ferrocarril. Durante dicho período, el mercado inmobiliario tuvo un importante desarrollo en la ciudad, en la cual se ejecutaron significativos proyectos de edificación en altura, tanto de viviendas como de oficinas. Los precios de las unidades inmobiliarias en dicho período fluctuaron entre las U.F. ${ }^{9} 2000$ y las U.F. 11.000, concentrándose principalmente en el tramo de U.F. 3.000 a U.F. 5.000 correspondientes a viviendas en altura. Condicionado por la crisis asiática de 1997, el mercado inmobiliario local experimentó una reestructuración de la oferta, con valores del rango U.F. 1.000 a U.F. 2.000, dirigida a segmentos medios compuestos principalmente por trabajadores dependientes, profesionales y técnicos (Cámara Chilena de la Construcción CCHC, 2008), esto es corroborado por Cattaneo (2011) al plantear que la "embestida de la onda depresiva de la crisis asiática puso término al ciclo de crecimiento del sector inmobiliario" (:10) orientado a clases altas y se redefinió hacia clases medias. Ahora bien, esto sólo generó la creación de un nuevo vehículo de inversión que provocó cambios en las estrategias de las administradoras de fondos de inversión, la aprobación de nuevas figuras legales y la renovación del mercado inmobiliario, lo cual se concretó con la alianza público-privada viéndose plasmada en los acercamientos entre la I. Municipalidad de Iquique con su asesoría urbana y la Cámara Chilena de la Construcción.

Lo anterior se vuelve explícito en la Fig. 2, que denota una consolidación del boom inmobiliario sobre el área de inundación de la ciudad en el primer periodo, el cual está asociado a las amenidades ambientales y recreativas que da la cercanía al mar y que tiene un efecto positivo en el aumento del valor del suelo. Como plantea la División de Servicios Externos, SEREX (2007:73) "la mayor concentración de los departamentos en I quique se agrupan en ciertos sectores como el centro-poniente, la Península Cavancha y por la costa hacia el sur".

Este patrón de localización ha consolidado la zona costera como un eje estructurante del desarrollo urbano, evidenciando la importancia de esta como "el elemento básico que ordena los valores de suelo (de mayor a menor valor). Sumado a esto, también se

9 Valor promedio UF al año 1990 es de $\$ 6.640,54$. 
reconoce la existencia de un patrón en donde el precio del suelo aumenta hacia el sur" (SEREX, 2007:72). Revisando la Fig. 2 se evidencia que en Iquique los altos precios de suelo impiden el desarrollo de proyectos inmobiliarios para sectores con menor capacidad de pago, generándose preferentemente construcciones orientadas a los grupos medios altos y altos (Centro de Investigación en Políticas Públicas de Tarapacá CIPTAR, 2013:23).

Entonces, la oferta inmobiliaria entre los años 1990-2010, se aferró al patrón de relación con el mar, emplazándose sobre el área de inundación por tsunami. "Respecto a los permisos de edificación, es posible identificar que en la ciudad de Iquique el desarrollo en los últimos doce años ha apuntado a la construcción vertical" (Herrera, 2014:33).

Sin embargo, se evidencia que durante el período 2010-2015 la oferta inmobiliaria presentó una importante variación en su localización, emplazándose sobre espacios que históricamente presentaban menor valor de suelo y lejanos de la cota de inundación por tsunami, como lo son las poblaciones norte de la ciudad, comprendidos entre la Zona industrial y la calle Sotomayor (dos barreras físicas y simbólicas). Estas áreas representan para la planificación urbana un desafío, debido a que los instrumentos normativos dejan a merced del mercado inmobiliario a los habitantes marginales ${ }^{10}$ de estas áreas, y por otro lado, generan una oportunidad al gobierno local para realizar cierta limpieza social (social cleansing) (González y Hodkinson, 2014) debido a que son áreas que cargan con la mancha de lugar (Wacquant, Slater y Pereira, 2014). Frente a esto es interesante analizar por qué se genera un desvío de la mirada del privado sobre estos territorios, conocer a qué responde su localización y cuáles han sido los efectos de los proyectos inmobiliarios en estos barrios. Para ello, se deben comprender las dinámicas que ocurren en estas áreas y el porqué de la deshonra espacial.

\section{Estigma territorial, hiperguetos y limpieza social: "el problema" de las poblaciones del pericentro norte de Iquique}

Iquique se perfila como escenario favorable para la penetración de inversión inmobiliaria en espacios de desinversión debido principalmente a que no existe ningún instrumento de planificación territorial que garantice la permanencia de hogares de bajos ingresos. Sumado a esto, las poblaciones pericentrales de la zona norte de la ciudad están experimentando, desde la década de 1970, procesos socioespaciales de guetización e hiperguetización (Labbé, 2014), que devalúa el precio del suelo, alcanzando precios por debajo de las 2 UF/m² (Fig. 2).

Tal como plantean Labbé (2014), Palma (2014) y Contreras (2012), algunas manzanas del centro y pericentro han acogido un número creciente de migrantes latinoamericanos y nativos chilenos de bajos ingresos que habitan en viviendas deterioradas, formando espacios de homogeneidad social al interior de la ciudad, que son etiquetados como guetos. Este fenómeno no es nuevo. Desde la década de 1960 en la ciudad, se establecieron espacios homogéneos asociados a tomas de terreno ilegales por migrantes interurbanos en los márgenes de la ciudad, que eran habitados por personas con conciencia de clase, logrando establecer instituciones y vínculos comunitarios que les permitirían satisfacer demandas básicas relacionadas con la

10 Según Bauman (2011), son una parte de la población situada en el extremo inferior de la distribución social de riquezas e ingresos, y además hace referencia su posición dentro de la ciudad. 
vivienda. Hoy en día, estos espacios han mutado y se configuran como zonas que cargan con un fuerte estigma territorial asociado entre otras cosas, al tráfico de drogas, la delincuencia y la informalidad económica.

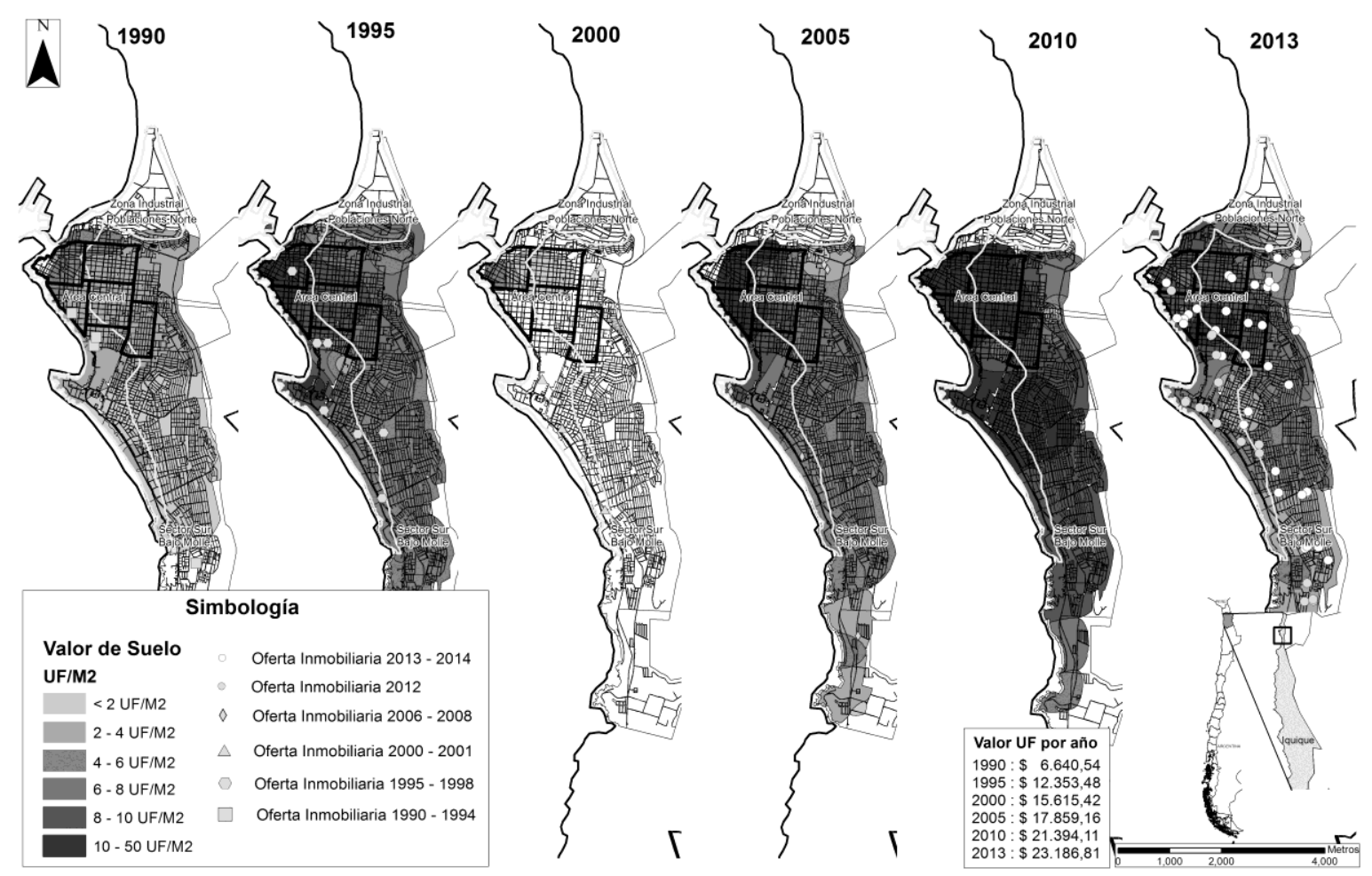

Fig. 2 Evolución valor de suelo y oferta inmobiliaria

Fuente: Elaboración propia a partir de Fondecyt 1112124.

Desde la literatura anglosajona ha penetrado un nuevo concepto, el hipergueto (Wacquant, 2001), que da cuenta de un fenómeno de exclusión exacerbado que se equipara con la visión latinoamericana del gueto (Salcedo, 2008). Dicho fenómeno se caracteriza por un deterioro en el entramado social del gueto y por poseer habitantes con movilidad social en descenso, donde predomina un crecimiento sin freno de la economía informal y criminal, pero por sobre todo "un lugar de dónde los residentes buscan huir desesperadamente" (Wacquant, 2001:83).

Las zonas homogéneas de estratos populares iquiqueñas surgen debido a la oleada de tomas de terreno en los espacios borde-cerro de la ciudad, como respuesta al problema del déficit habitacional. Estos espacios homogéneamente pobres se caracterizan por su falta de inversión pública-privada provocando procesos de estigma y segregación. Se consolidaron en el sector al norte de la ciudad poblaciones emblemáticas como la John Kennedy (actual Jorge Inostrosa, Cárol Urzúa, Dínamo, Progreso) o la Villa Quitasoles. Labbé (2014) plantea que en la década de 1980 ocurrió el quiebre y la transformación hacia una forma de segregación más aguda: el hipergueto. Los años 80 fueron un período clave en la transformación de las relaciones al interior de las poblaciones iquiqueñas, la formación de más de once campamentos que se asentaron en el pericentro de la ciudad, sumado a la crisis económica que enfrentaba el modelo de ajuste estructural en el país (De Mattos, 2014), hacía que 
más sureños optaran por migrar en busca de un futuro prometedor en ciudades norteñas. Esta exacerbación del fenómeno hizo que la escala de las poblaciones cambiara y cada vez fuera más difícil la organización vecinal. Se hipotetiza que junto con la masificación del fenómeno de la marginalidad se produjo la desvinculación, el miedo y el desconocimiento hacia los vecinos, producto de las medidas restrictivas impuestas en dictadura $(1973)^{11}$. Esto generó que a la larga los vínculos comunitarios que en un momento fueron sólidos y estrechos, se fragmentaran. Lo anterior dio lugar a un espacio estigmatizado, violento y sin organización comunitaria que puede ser considerado bajo la lógica de Wacquant (2001) como un hipergueto moderno.

La población J orge Inostrosa (englobando a todas las poblaciones del pericentro norte) ha sido catalogada por los medios de comunicación local y el imaginario social, como un sector caracterizado por la violencia, el consumo y tráfico de drogas. Las antiguas estructuras sociales que tuvieron una importancia fundamental en la organización de la población, tales como el Club Deportivo, la Junta de Vecinos, el Centro de Madres y otras asociaciones voluntarias, ya no existen. Ahora el rol protagónico en la sociabilidad del barrio es asumida por la droga (Guerrero, 2013). Sin embargo, la población no siempre fue un depósito de patologías urbanas. En su fundación, durante la década de 1960, era un lugar donde la población estaba relacionada con las pesqueras y el ferrocarril, además las instituciones comunitarias daban vida a la población: La Junta de Vecinos, la Iglesia, el circo y el club de Básquetbol. Durante la década de 1980, debido al quiebre de la industria, la imposición de un modelo neoliberal y la represión impuesta por la dictadura, los vínculos comunitarios se rompieron y dieron paso a un lugar carente de institucionalidad social, donde predomina la violencia urbana y el desconocimiento entre los propios vecinos.

Estos hiperguetos se caracterizan principalmente por la mancha de lugar o estigma territorial que cae sobre ellos (Wacquant, 2001). Ruiz-Tagle (2016) usa la definición de Wacquant et al (2014) para describir la estigmatización territorial como una representación simbólica objetiva a través de lenguajes y símbolos plasmados en un lugar determinado, lo cual conlleva a asociar lugares con posiciones sociales específicas y su uso para designar una clase social o raza, como es el caso del sector nororiente iquiqueño. El impacto de la estigmatización territorial puede observarse en tres aspectos generales: 1) psicológicos, en cuanto a la erosión del sentido de pertenencia 2) institucionales, en cuanto a las inversiones, lo cual deteriora la calidad de vida y la cantidad de servicios, y 3) sociales, en cuanto a la fragmentación social y políticas públicas. La estigmatización territorial no sólo es una forma de poder simbólico, sino que también puede ser parte de una estrategia de renovación urbana, insistiendo en el carácter degradado y patológico del barrio (Ruiz-Tagle, 2016). En el sector nororiente este estigma ha generado disparidad en términos de valor de suelo. En promedio el valor en estos espacios alcanza alrededor de las 2-15 uf $/ \mathrm{m}^{2}$ para el 2013 (SEREX, 2007). Por otro lado, el sector sur, en específico la franja longitudinal borde mar que va desde Cavancha a Bajo Molle es un polo que presenta los valores de suelo más elevados de la ciudad (entre $50 \mathrm{uf} / \mathrm{m}^{2}$ y $60 \mathrm{uf} / \mathrm{m}^{2}$ ) (CCHC, 2013) (Fig. 2). Con estos datos es posible dar cuenta de las disparidades territoriales que enfrenta la ciudad de Iquique, y vienen a corroborar cómo estos espacios que presentan una tacha

11 El colapso del modelo I.S.I., hizo que se perdiera todo vínculo con el mercado del trabajo, convirtiendo a estas poblaciones en espacios de desocupación y desempleo, con lo cual el trabajo informal e ilegal no tardó en reemplazar las antiguas ocupaciones. Con la dictadura las nuevas autoridades militares revirtieron la tendencia intervencionista a través de un drástico programa de estabilización, sino también dejaron de invertir y redujeron su gasto social (Labbé, 2014). 
de lugar son sectores de desinversión, donde el capital puede anclarse espacialmente y así fijar sus intereses por sobre los de la comunidad local, carentes de cualquier estrategia para defenderse.

Un punto a destacar es que estas áreas del norte de Iquique hoy se presentan como espacios de oportunidad, por un lado para el gobierno local, con el fin de plasmar el programa de limpieza social que viene desarrollando desde algunas décadas, expulsando población, erradicando campamentos hacia la comuna de Alto Hospicio y el sector Playa Lobitos, apoyándose sobre la premisa de escasez de suelo. Por otro lado, como una oportunidad para el inmobiliario de capturar la renta potencial generada por estos bajos valores de suelo, incentivando el desplazamiento de población vulnerable. Otro punto interesante es la importancia de la localización de estas poblaciones (cercanía al centro) y el porqué del avance de la oferta inmobiliaria sobre estos terrenos. Smith (1996) lo detalla señalando que el atractivo del suelo urbano reside en su ubicación, accesibilidad, tecnología y trabajo invertido en su mejoramiento ${ }^{12}$. De esta forma, el valor de suelo es una creación social o colectiva, dado que 1) el valor de la centralidad y la accesibilidad es otorgado por la sociedad, y 2) el suelo urbano concentra inversión social acumulada en el transcurso de la historia. Sin embargo, los derechos de propiedad privada permiten a los dueños apropiarse de esa inversión social mediante la captura de una renta base.

Cada año se incrementan o disminuyen las diferencias entre la renta base y otra potencial, derivada de los posibles usos y aprovechamiento del suelo con nuevos usos y densidades construidas: ésta es la renta diferencial. En este marco el ciclo de inversión-abandono es una destrucción creativa que redistribuye costos y beneficios a los propietarios (Delgadillo; 2010, p.838).

Es así como estas poblaciones hoy se encuentran en la frontera geográfica de la gentrificación, frontera la cual según Smith (1996) permite "reproducir las diferencias sociales entre el nosotros y el ellos, para la diferenciación histórica entre el pasado y el futuro, para la diferenciación económica entre el mercado existente y la oportunidad de ganancia" (1996:299). La frontera de la gentrificación representa, en realidad, una línea que divide las zonas del paisaje urbano en las que se desinvierte (barrios interiores y pericentrales), de aquellas en las que se reinvierte (borde costero). Frente a esto, en la ciudad de Iquique se está potenciando una nueva forma de urbanismo, la cual presenta rasgos muy diferentes a los acontecidos entre la década de 1990 y 2000 . Ésta tiene una estrecha relación con los sucesos socionaturales acontecidos durante estos últimos cinco años en el país. Esta frontera incipientemente se comienza a desplazar sobre el espacio de desinversión, lo cual ha generado distintos conflictos que se observan de manera espacial como también social en las poblaciones. Estas áreas, como se planteó anteriormente, son vistas como espacios de oportunidad frente a los discursos ideológicos implementados. Cabe preguntarse entonces si son las poblaciones pericentrales del norte un nuevo foco de localización de la oferta inmobiliaria, y si es así, cuál fue el efecto detonador para la relocalización de esta oferta.

12 En el sector norte, existe un plan de ampliación vial que unirá el puerto con la ciudad, tal proyecto provocará la erradicación de población, específicamente del sector Las Cabras, población de la norte de la ciudad. 


\section{Terremoto en el Norte Grande: ¿oportunidad frente a la escasez de suelo?}

El martes 1 de abril del 2014 a las 20:48 un fuerte sismo magnitud 8,2 $\mathrm{M}_{\mathrm{w}}$ azotó el norte grande de país, posteriormente cercano a las 21:05 un tsunami de 1,62 metros afecto las costas iquiqueñas. Claramente esta catástrofe no solo dejó efectos psicológicos, físicos e infraestructurales. También es posible observar otras consecuencias asociadas al terremoto y que recaen no solo en los barrios y/o poblaciones afectadas, sino sobre la vida cotidiana de estas áreas. La destrucción de las viviendas en los espacios más vulnerables de la ciudad fue vista como como oportunidad por ciertos actores que inciden en el diseño de la ciudad, transformando la planificación urbana en una planificación de corte empresarial.

Si bien, antes del terremoto existía una tendencia por parte del inmobiliario de buscar los espacios de menor valor de suelo, éstos debían tener ciertas características interesantes en términos de conectividad, accesibilidad y seguridad, intensificando esta última, debido al surgimiento de un miedo colectivo por parte de la ciudadanía frente al incipiente hecho telúrico, post terremoto 2014. Este miedo se acrecentó siendo aprovechado por el ente público y privado para promover sus propias agendas, lo cual volcó la mirada hacia las poblaciones pericentrales norte que tanto tiempo estuvieron a merced del deterioro.

De esta forma el terremoto y posterior tsunami generó sobre estos territorios tres efectos en el área de las poblaciones. El primero de ellos tiene relación con el aumento de sitios eriazos (Fig. 3). El segundo de ellos, el surgimiento de una población flotante sin solución habitacional, cuya única opción es la relocalización en la comuna de Alto Hospicio. Y finalmente, una oferta inmobiliaria enfocada a un habitante con un poder adquisitivo mayor en zonas aparentemente seguras. Al observar la Fig. 3, se corrobora lo planteado, como también muestra luces de los efectos inmediatos en términos de usos de suelo.

Es así que destaca como uno de los efectos más importante el aumento de los puntos de venta de terrenos en las poblaciones, debido a que la reconstrucción de las viviendas dañadas era imposible de llevar a cabo por parte de las familias ${ }^{13}$ fomentando un desplazamiento de éstas hacia sectores donde se presentan proyectos de viviendas de interés social, específicamente hacia Alto Hospicio. Sumado a esto, se observa la variación en el uso de suelo destinado a residencia, el cual post terremoto muestra una diversificación y aparición de nuevos usos antes inexistentes en el sector, debido a la revalorización del área, que ha provocado que privados se interesen en invertir allí para responder a la nueva demanda de población de estratos medios.

\subsection{Desplazamiento de la frontera de la gentrificación: el caso de la población San Carlos Ferronor}

En el primer apartado, y luego de haber expuesto las causas que llevaron al desplazamiento de proyectos inmobiliarios sobre espacios estigmatizados, es interesante mostrar lo sucedido en la población San Carlos Ferronor, la cual se ubica en el sector norte de la ciudad. En ella se observa un incipiente fenómeno de gentrificación, entendiéndolo como un desplazamiento y reemplazo de una clase

13 Una vivienda en el sector de las poblaciones norte se vende en promedio a $\$ 25.000 .000$, con este dinero no se puede comprar otra vivienda dentro de la ciudad de Iquique. Tampoco tienen recursos para reconstruirla, ya que un $70 \%$ de las familias pertenecen a los estratos socioeconómicos E (clase baja) y D (clase media baja), 1.125 personas son analfabetas y un $13 \%$ de las adolescentes entre 12 y 16 años presenta embarazo adolescente (Labbé, 2014). 
obrera (antiguos residentes de origen pampino y ferroviario) por grupos medios. Sin embargo, el elemento más distintivo dentro de esta particular gentrificación está relacionado con el papel preponderante de las inmobiliarias tanto en la apropiación de la revalorización de zonas originalmente deterioradas, como en la ejecución de una renovación urbana en base a densificación en altura (López, 2013; Inzulza y Galleguillos, 2014). Este proceso de reconfiguración físico, social y cultural se aleja de casos como el descrito por Schlack y Turnbull (2009), vinculados a una gentrificación de gentries artistas, en donde los cambios no solo se producen en algunas manzanas de un barrio, sino que incluso en predios al interior de las manzanas, generándose una alta heterogeneidad de grupos sociales dentro de un mismo espacio.

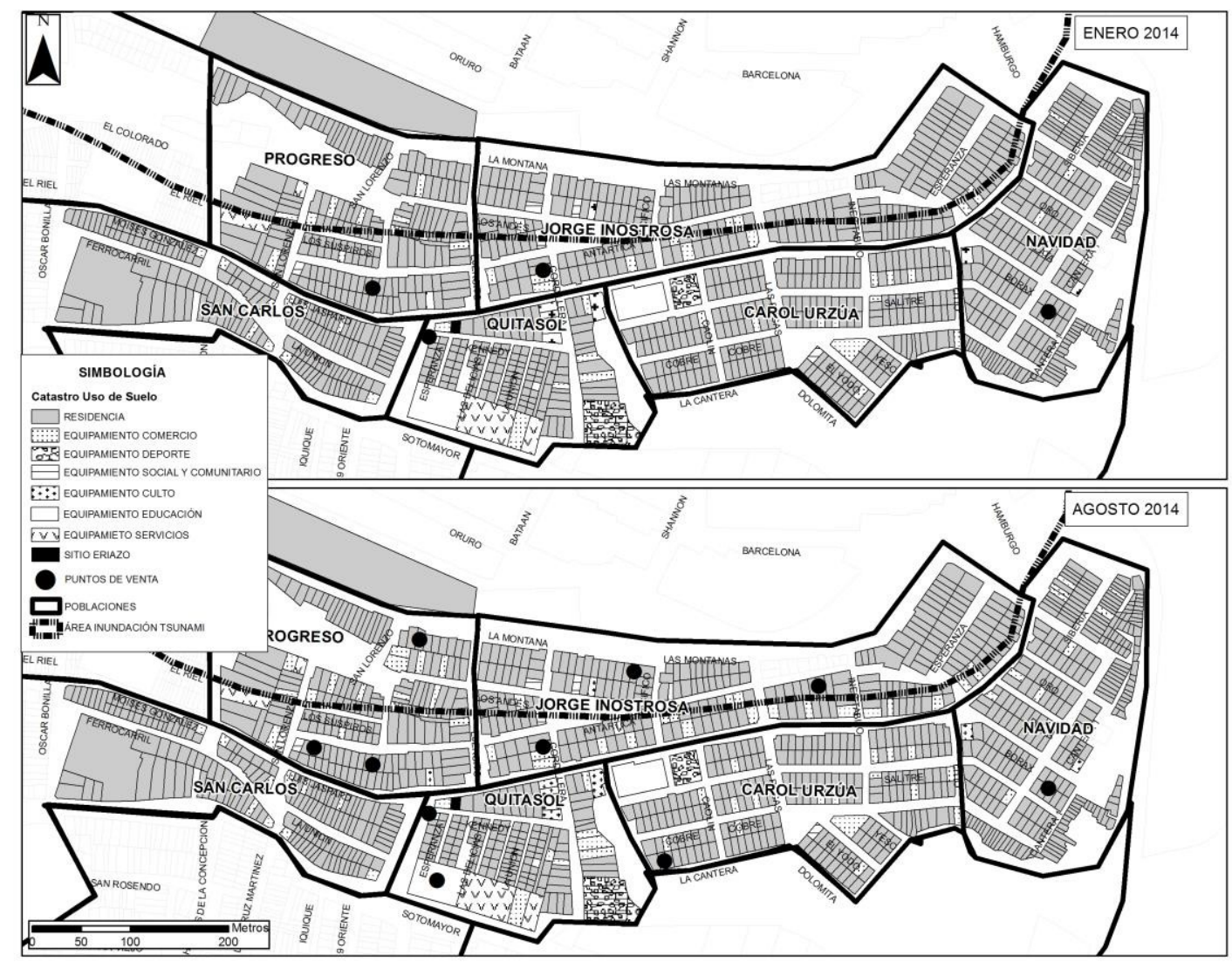

Fig. 3 Variación en el uso de suelo pre y post terremoto 2014

Fuente: Elaboración propia a partir de terrenos aplicados en el área de estudio, Fondecyt 1112124.

Es así como la localización del Edificio Nuevo Barrio ${ }^{14}$ viene a ser el primer antecedente para discutir un proceso incipiente de gentrificación en el área de estudio. San Carlos Ferronor es la población que se encuentra a solo pasos del centro histórico de la ciudad, conectada principalmente por la Av. Sotomayor, que marca la transición entre la ciudad informal (tomas de terreno) y ciudad consolidada (centro histórico). La población nace a fines de los años 50, bajo la óptica de la autoconstrucción y sin ningún tipo de planificación, con población principalmente de origen pampino, pero también asociados al ferrocarril, es decir, con la clase obrera de la época (Guerrero,

14 El edificio Nuevo Barrio es obra de la Inmobiliaria Río Quiapo, su dirección es Oscar Bonilla №26 y los valores de sus viviendas parten desde las 1.669 UF. 
2007). Hoy San Carlos Ferronor ha visto una reconfiguración en términos de su población, por un lado con la llegada de habitantes de menores ingresos como son los migrantes latinoamericanos (Palma, 2014) y por otro, un incipiente arribo de clases medias por la localización del proyecto Edificio Nuevo Barrio. Esta información es corroborada por la Fig. 4 en la cual se observa la variación de los GSE en las poblaciones norte, destacando el área de San Carlos Ferronor como una de las poblaciones que presenta un aumento en los grupos catalogados como C3 (clase media), según GeoAdimark GFK.

La llegada de grupos con mayor poder adquisitivo ha generado en el corto plazo un desplazamiento de residentes históricos hacia otros espacios de homogeneidad social, alejados del área de servicios y trabajo, como es la comuna de Alto Hospicio. Este efecto es uno de los rasgos más característicos en un proceso de gentrificación, aunque a éste se suman otros costos a largo plazo que tenderían a ocurrir si esta frontera de la gentrificación se sigue desplazando. Sí esto ocurriera, provocaría una fractura en los barrios y/o poblaciones, intensificando la disminución de tejido social que acarrean desde la década de 1980. El desalojo ${ }^{15}$ paulatino de residentes incitará un quiebre en el capital social, se desplazarán comercios y servicios populares, y por otro lado se encarecerá a largo plazo el valor de suelo generando una pérdida de vivienda asequible (Delgadillo, 2010), esto inducirá a que población vulnerable como los antiguos residentes y hoy los migrantes latinoamericanos se vean forzados a acceder a otros sectores de la ciudad alejados de sus redes sociales y/o familiares o bien ser expulsados formando nuevos espacios de desinversión, es decir, zonas hiperguetizadas.

La llegada de grupos con mayor poder adquisitivo ha generado en el corto plazo un desplazamiento de residentes históricos hacia otros espacios de homogeneidad social, alejados del área de servicios y trabajo, como es la comuna de Alto Hospicio. Este efecto es uno de los rasgos más característicos en un proceso de gentrificación, aunque a este se suman otros costos a largo plazo que tenderían a ocurrir si esta frontera de la gentrificación se sigue desplazando. Sí esto ocurriera, provocaría una fractura en los barrios y/o poblaciones, intensificando la disminución de tejido social que acarrean desde la década de 1980. El desalojol6 paulatino de residentes incitará un quiebre en el capital social, se desplazarán comercios y servicios populares, y por otro lado se encarecerá a largo plazo el valor de suelo generando una pérdida de vivienda asequible (Delgadillo, 2010), esto inducirá a que población vulnerable como los antiguos residentes y hoy los migrantes latinoamericanos se vean forzados a acceder a otros sectores de la ciudad alejados de sus redes sociales y/o familiares o bien ser expulsados formando nuevos espacios de desinversión, es decir, zonas hiperguetizadas.

15 Se ha observado en el área central procesos de desalojos violentos llevados a cabo por el Estado y la fuerza pública, con el fin de concretar proyectos inmobiliarios como el edificio Urbano.

16 Se ha observado en el área central procesos de desalojos violentos llevados a cabo por el Estado y la fuerza pública, con el fin de concretar proyectos inmobiliarios como el edificio Urbano. 

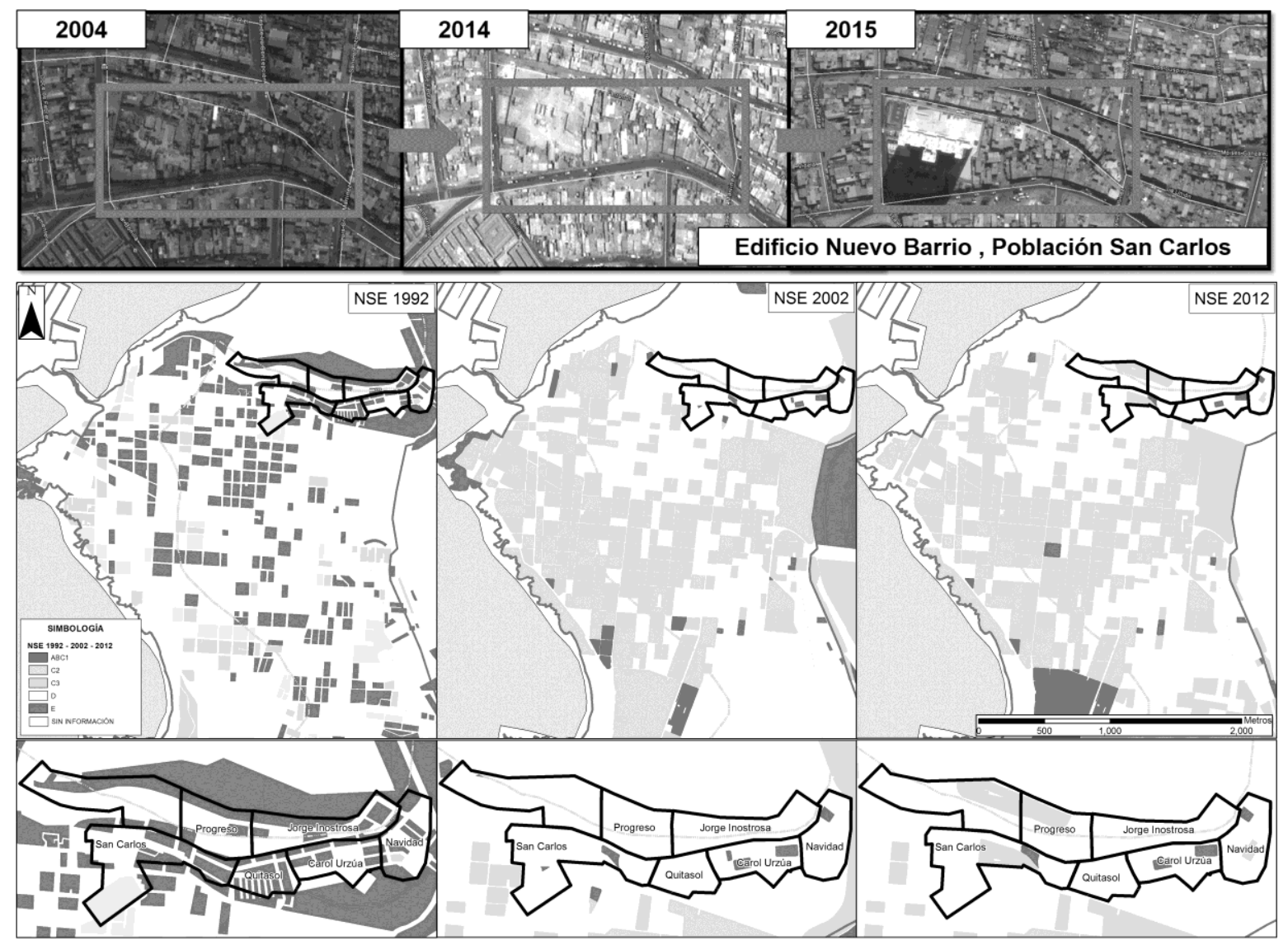

Fig. 4 Evolución GSE y oferta inmobiliaria en la población San Carlos Ferronor

Fuente: Elaboración propia a partir GSE entregados por GeoAdimark GFK, plataforma Google Earth y catastro en terreno, Fondecyt 1112124.

\section{Discusión}

El fenómeno que está invistiendo y reconfigurando los barrios de la ciudad de Iquique, es parte de un proceso de recuperación o rehabilitación de barrios, pueblos costeros o centros históricos del llamado tercer mundo, para destinarlos fundamentalmente al consumo de clases medias. Para Lees, Slater y Wyly (2008) en Delgadillo (2010), este urbanismo neoliberal, que está afectando a las ciudades del mundo entero, es una forma de neocolonización de las clases medias. Este hecho demostraría que la gentrificación se ha exportado a nuevos territorios como ciudades intermedias, que permitiría reinterpretaciones del fenómeno. En la literatura anglosajona, se abre el interés por abordar ciudades intermedias y/o ciudades provinciales (González y Hodkinson, 2014), bajo el contexto de que la gentrificación puede representar una estrategia de desarrollo urbano (independiente del tamaño de la ciudad) y económico para una localidad. En esta línea, los procesos de urbanización en gran parte de los países (en especial los que están en vías de desarrollo) son económicamente sustentados por inversiones extranjeras (Harvey y Smith, 2005) y/o privadas, produciéndose con ello un boom inmobiliario bajo la lógica de la destrucción creativa que ha despojado de sus espacios y destruido sus tipos de vida (Harvey, 1994) a los que tienen menores ingresos en pos de la revitalización, de la renovación urbana, de un nuevo mundo urbano para los nuevos estilos de vida. 
No deja de ser paradójico, bajo la racionalidad de los negocios, que la intervención de un sector inmobiliario, en coordinación con los gobiernos locales, se realice en zonas que cargan con fuertes estigmas negativos dentro de la ciudad, en otras palabras,

¿cómo se puede vender un departamento o casa, a un precio conveniente, que tiene por vecinos a una población asociada a la delincuencia y/o la drogadicción? Un caso emblemático y que puede ilustrar un sinsentido como el que ocurre en Iquique, es lo que sucedió en el sector de Craigmillar en Edimburgo, Escocia, este pueblo había alcanzado tal estigma de paria, que el gobierno local pensaba que no había ninguna esperanza. La estrategia fue demoler parte de la ciudad, desplazando una gran cantidad de hogares de bajos ingresos hacia otras zonas de Edimburgo, fomentando el arribo de grupos de mayor estatus social para promover su reactivación. A través de esta gentrificación, se eliminó el corazón de Craigmillar en un proceso que puede identificarse como de limpieza social (González y Hodkinson, 2014).

Ésta es una estrategia urbana global vinculada a la nueva globalización neoliberal y al nuevo urbanismo, donde el gobierno de la ciudad actúa más como un agente empresarial que promueve la acumulación del capital, que como regulador del mercado y protector de residentes desfavorecidos. (Delgadillo, 2010: 842).

La gentrificación según Lees, Slater y Wyly (2008) combina un intenso financiamiento de vivienda en régimen de propiedad privada para los hogares de ingresos medios, un nuevo urbanismo conservador basado en una moral invasora que justifica los desplazamientos de población de bajos ingresos, una forma de gestión urbana de corte empresarial que promueve la ciudad para los negocios, y una regulación penal sobre los pobres (siempre sospechosos de cometer actos delictivos). Lo interesante es que se comprueba lo planteado por Wacquant, Slater y Pereira (2014)

La tacha que recae sobre un lugar puede ser alimentada, utilizada y manipulada por intereses privados (tales como los medios de comunicación, empleadores y empresas inmobiliarias) y funcionarios públicos (tanto en el campo político como en el burocrático) para promover sus propias agendas, de manera que la deshonra espacial opera como un eje central y simbólico entre desigualdad y marginalidad en la metrópolis. (p.3).

Sumado a lo expuesto anteriormente, cabe destacar y corroborar la intensificación del fenómeno de la gentrificación y la movilidad del capital en las ciudades que han estado sometidas a desastres socio naturales, como Constitución (Contreras y Beltran, 2014) o Talca (Inzulza 2013). Los efectos post desastres llevan a apreciar la capacidad del capital de anclarse en un espacio de desinversión con el fin de capitalizar con los escenarios de reconstrucción en ciudades chilenas como es el caso de Santiago, Constitución y Talca. I quique no se encuentra alejada de esta tendencia, siendo parte del circuito del nuevo urbanismo neoliberal que busca espacios para capturar la renta potencial. Este proceso de verticalización y densificación muestra una nueva cara en la ciudad la cual se encuentra vinculada a la seguridad y conexión que presentan los espacios de desinversión y estigmatizados para emplazar la nueva oferta inmobiliaria que viene abastecer a una urbe que enfrenta a diversas amenazas tanto socio- naturales como también ideológicas.

\section{Conclusión}

A partir de esta investigación podemos observar las transformaciones urbanas asociadas a la ciudad de Iquique en los últimos años, con énfasis en los procesos más 
recientes que están sucediendo en este territorio. Es así como se identifica un proceso de turistificación desde el año 1990 hasta 2010, en donde la oferta inmobiliaria se concentró en la zona costera, caracterizándose por construcciones verticales de oficinas y viviendas destinadas a los sectores medio-alto y alto de la población. Sin embargo, es a partir del año 2010 que estas transformaciones comienzan a perfilarse como gentrificación o nuevo urbanismo colonizador, el cual se asienta principalmente en la zona pericentral norte de la ciudad.

Este fenómeno, característico hasta ahora de las grandes ciudades en los países del tercer mundo, comienza a desarrollarse hoy en ciudades intermedias, tales como Iquique. Es así como en este núcleo urbano tanto el sector privado (inmobiliarias) como público (gobierno local) empiezan a invertir en la zona pericentral norte, con un bajo valor de suelo, amparados en el discurso de la escasez relativa de suelo que experimenta la ciudad, la necesidad de relocalización de oferta inmueble en zonas seguras de desastres naturales, posterior al terremoto de abril del 2014, así como también al aprovechamiento del estigma territorial que posee este sector, el cual se caracteriza por representar un hipergueto, con población empobrecida compuesta por residentes históricos de origen pampino e inmigrantes latinoamericanos que han llegado en el último tiempo, además de sus patologías urbanas, tales como violencia y tráfico de drogas. Sin embargo, las políticas e inversiones aplicadas en esta zona responden a un aprovechamiento por su accesibilidad al centro, y esconden una motivación de limpieza social, por parte del gobierno local, así como de captura de renta potencial, por parte de las inmobiliarias. Claro ejemplo de lo nombrado son las obras previstas que buscan consolidar la conectividad entre el puerto y la ciudad, la cual prevé la expropiación de 20 familias. Estás obras anunciadas desde el 2009 aún no se concretan debido a la lucha existente entre los habitantes y el SERVIU por los valores entregados como compensación los cuales no permiten la reubicación de los hogares dentro de la misma área (Solimano, 2009) hablando de un desplazamiento exclusionario (Marcusen, 1985)

Los efectos generados por esta gentrificación post desastre o nuevo urbanismo colonizador en el sector pericentral norte de Iquique son múltiples y muy perjudiciales, desde una perspectiva tanto social como desde el punto de vista de las dinámicas urbanas generales de la ciudad. Por una parte, producen una revalorización de suelo y diversificación de sus usos, consecuentemente con la llegada de un nuevo tipo de residente a la zona, pertenecientes a sectores medio-altos y altos, lo que suscita finalmente un desplazamiento de población histórica y de inmigrantes con menor poder adquisitivo, hacia el sector sur de la ciudad, particularmente la zona de Alto Hospicio, así como también una distribución inequitativa de los recursos en la ciudad de Iquique.

Es a partir de los anteriores resultados señalados que podemos responder asertivamente a la pregunta planteada en el principio de esta investigación, la cual da cuenta de la inversión de desarrolladores inmobiliarios en el sector pericentral norte de la ciudad de I quique, en específico en el barrio San Carlos Ferronor con el Edificio Nuevo Barrio, que aprovecharon por un lado, el estigma con el que cuenta esta área, que devalúa el precio de su suelo, y por otro lado, el carácter de zona segura ante desastres naturales - definida por el Servicio Hidrográfico y Oceanográfico de la Armada de Chile (SHOA) y la Oficina Nacional de Emergencia (ONEMI) (2011)-, originando un proceso de transformaciones espaciales que ha generado desplazamiento de población de bajos ingresos en beneficio de la de mayores ingresos, intensificándose a partir del año 2014 después del terremoto que azotó esta ciudad. Por tanto, podemos establecer tres reflexiones principales en torno a los resultados obtenidos, las cuales se centran 
en las implicancias sociales y espaciales de las nuevas dinámicas urbanas desarrolladas hoy en día en la ciudad de Iquique, que aportan a la discusión actual que se está realizando en el campo de los estudios urbanos.

En primer lugar, se encuentra la conceptualización del valor del suelo como resultado de una construcción social, la cual se configura a partir de la importancia social entregada a las zonas en cuanto a su ubicación y accesibilidad, en relación al entramado urbano general en el que se inscriben, así como también a la inversión infraestructural acumulada en el transcurso del tiempo, que las transforman en áreas de oportunidad. En segundo lugar, podemos señalar la importancia que cobra el estigma territorial de una zona, el cual desincentiva la inversión y mantiene un valor de suelo urbano bajo, propiciando la imagen del hipergueto al interior de ésta, en donde el gobierno local justifica su intervención con el fin de desbaratar polos de delincuencia y vulnerabilidad, y las inmobiliarias se apoyan en la idea de recuperación y rehabilitación de barrios. Lo anterior tiene como consecuencia directa la emergencia de procesos de gentrificación, donde el boom inmobiliario termina por arrasar espacios tradicionales, provocando la pérdida de relaciones sociales construidas en el tiempo entre sus habitantes, y de los estilos de vida característicos asociados al lugar. Por último, cabe reflexionar respecto al rol que hoy en día cumplen los gobiernos locales en cuanto a la planificación y ordenamiento de las ciudades (específicamente aquellas que han sufrido los embates de la naturaleza) los cuales actúan como agentes empresariales que promueven la acumulación de capital y posibilitan el ambicioso accionar de inmobiliarias sobre barrios vulnerables, en vez de funcionar como reguladores del mercado y defensores de la población urbana más desfavorecida.

Es así como esta investigación deja abiertas algunas interrogantes y pistas para seguir estudiando en el futuro. Por un lado, se encuentra el incipiente proceso de gentrificación que se está desarrollando en lquique como escenario post desastre, el cual sería interesante de observar a lo largo del tiempo, viendo las tendencias y características que vaya adoptando, para relacionarlo con la teoría general (de la capitalización del riesgo) identificando sus continuidades y quiebres. Por otro lado, está la importancia que tiene este tipo de proceso en ciudades de orden intermedio, el cual es emergente y serviría analizar para establecer un posible patrón general de comportamiento en este tipo de núcleos urbanos, para especular respecto a las medidas de mitigación ante sus efectos negativos de manera específica y atingente a su realidad local.

\section{Referencias}

Bauman, Z. (2011). Desigualdad social ¿El problema más grave del siglo XXI? Recuperado de http://istmo.mx/2013/04/desigualdad-social-elproblema-mas-grave-del-siglo-xxi/

Cámara Chilena de la Construcción, CCHC. (2008). Biblioteca Cámara Chilena de la construcción. Recuperado de http://www.biblioteca.cchc.cl/datapicture/21614.pdf

Cámara Chilena de la Construcción, CCHC. (2013). Recuperado de http://www.cchc.cl/2013/07/directivos-regionales-sereunen-con-gobernador-de-iquique/

Cattaneo, R. (2011). Los fondos de inversión inmobiliaria y la producción privada de vivienda en Santiago de Chile: ¿un nuevo paso hacia la financiarización de la ciudad? Revista EURE, 37(112), 5-22. 
Centro de Investigación en Políticas Públicas de Tarapacá, CIPTAR. (2013). Segregación residencial en Iquique y Alto Hospicio. Recuperado de http://tenred.cl/wpcontent/uploads/2013/05/NEWSLETTER-03-CIPTAR.pdf

Contreras, Y. (2011). Elecciones y anclajes residenciales de los nuevos habitantes del centro de Santiago: la experiencia del barrio Bellas Artes. Revista Transporte y Territorio, 4, 5883. Recuperado de http://repositorio.uchile.cl/bitstream/handle/2250/139723/eleciones$\mathrm{y}$-anclajes.pdf? sequence $=1$

Contreras, Y. (2012). Cambios socio-espaciales en el centro de Santiago de Chile: formas de anclarse y prácticas urbanas de los nuevos habitantes (Tesis para obtención del grado de doctor de Arquitectura y Estudios Urbanos). Recuperado de https://hal.archivesouvertes. fr/tel-00684955/document

Contreras, Y. (2014). La gentrificación de los barrios céntricos de Chile. Recuperado de http://www. patrimoniocultural.cl/607/articles-4468_pdf_1.pdf

Contreras, Y. y Beltrán, M. (2015). Reconstruir con capacidad de resiliencia: el casco histórico de la ciudad de Constitución y el sitio del desastre del terremoto y tsunami del 27 de febrero 2010. Revista INVI, 30(83), 79-115. Recuperado de https://doi.org/10.4067/s0718-83582015000100003

Delgadillo, V. (2010). Reseña de "Gentrification" de Loreta Lees, Tom Slater y Elvin Wyly. Economía, Sociedad y Territorio, 10(34), 835-846. Recuperado de http://www.redalyc.org/pdf/111/11115672010.pdf

De Mattos, C. (2014). Gobernanza neoliberal, financiarización y metamorfosis urbana. Santiago de Chile: Instituto de Estudios Urbanos y Territoriales, Pontificia Universidad Católica de Chile.

División de Servicios Externos, SEREX. (2007). Análisis de tendencias urbanas y zonas de gestión integrada. Iquique: Facultad de Arquitectura, Diseño y Estudios Urbanos, Pontificia Universidad Católica de Chile.

Figueroa, O. y Fuentes, L. (2009). Expansión urbana y desarrollo económico: el caso del sistema urbano Iquique-Alto Hospicio. Recuperado de http://geografia.uc.cl/images/serie_GEOlibros/del_pais_urbano/oscar_Figueroa_Luis_Fuen $\underline{\text { tes.pdf }}$

González, S. y Hodkinson, S. (2014). Gentrificación como política pública en una ciudad provincial: el caso de la ciudad de Leeds en el Reino Unido. Revista de geografía Norte Grande, 58, 93-109. https://doi.org/10.4067/s0718-34022014000200006

Guerrero, B. (2007). La ciudad y sus transformaciones. Memoria Urbana de Iquique. Revista de Ciencias Sociales, 19, 149-165. Recuperado de http://www.redalyc.org/pdf/708/70801909.pdf

Guerrero, B. (2013). Hasta que el cuerpo aguante. La dinámica sociocultural del consumo de drogas. Iquique: El jote errante. Centro de Investigación de la Realidad del Norte CREAR.

Harvey, D. (1990). La condición de la postmodernidad. Investigación sobre los orígenes del cambio cultural. Buenos Aires: Editores Amorrortu. 
Harvey, D. (2004a). Mundos urbanos posibles. En A. Martín (Ed.), Lo urbano en 20 autores contemporáneos (pp. 177-198). Barcelona: Ediciones UPC. Recuperado de https://bibliodarq. files. wordpress.com/2014/09/ramos-a-m-lo-urbano-en-20-autorescontemporc3alneos.pdf

Harvey, D. (2004b). El nuevo imperialismo: acumulación por desposesión. Buenos Aires: CLACSO.

Herrera, N. (2014). Oportunidades de desarrollo inmobiliario residencial, determinados por el nivel de inversión, caso de estudio Comuna de Iquique, Región de Tarapacá, Chile (Tesis de grado para optar al título de Arquitecto). Universidad de Chile, Santiago de Chile. Recuperado de http://repositorio.uchile.cl/handle/2250/130347

Instituto Nacional de Estadísticas, I NE. (2012). Resultados preliminares censo de población y vivienda. Recuperado de https://www.cooperativa.cl/noticias/site/artic/20120831/asocfile/20120831161553/result ados preliminares censo 2012.pdf

Inzulza-Contardo, J. (2013). ¿Gentrificación "a la medida" en Talca?: el caso del Barrio Las Heras. Trabajo presentado en el seminario El derecho a la ciudad en un escenario de reconstrucción y gentrificación: casos de estudio Talca y Constitución, Talca.

Inzulza-Contardo, J. y Galleguillos, X. (2014). Latino gentrificación y polarización: transformaciones socioespaciales en barrios pericentrales y periféricos de Santiago, Chile. Revista de geografía Norte Grande, 58, 135-159. https://doi.org/10.4067/s0718$\underline{34022014000200008}$

Labbé, G. (2014). Del gueto al hipergueto en el centro y pericentro de la ciudad de Iquique (Tesis de grado para optar al título de Geógrafo, Universidad de Chile, Santiago, Chile). Recuperado de http://repositorio.uchile.cl/handle/2250/130081

Lees, L., Slater, T., \& Wyly, E. (2008). Gentrification. New York: Routledge.

López-Morales, E. (2013). Gentrificación en Chile: aportes conceptuales y evidencias para una discusión necesaria. Revista de geografía Norte Grande, 56, 31-52. https://doi.org/10.4067/s0718-34022013000300003

Marcuse, P. (1985). Gentrification, abandonment and displacement; connections, causes and policy responses in New York City. Journal of Urban and Contemporary Law, 28, 195-240. Recuperado http://openscholarship.wustl.edu/cgi/viewcontent.cgi?article=1396\&context=law_urbanla $\underline{\mathrm{w}}$

Ministerio de Obras Públicas, MOP. (2005). Plan de Obras Públicas. Santiago de Chile: Autor.

Palma, P. (2014). Trayectorias residenciales y prácticas espaciales de los hogares migrantes latinoamericanos del centro y pericentro de la ciudad de Iquique (Tesis de grado para optar al título de Geógrafo, Universidad de Chile, Santiago, Chile). Recuperado de http://repositorio.uchile.cl/handle/2250/129886

Pantoja, J. (2015). Entrevista al presidente de la Red Social Iquique de la CCHC. (G. Labbé, entrevistador). 
Ruiz-Tagle, J. (2016). Territorial stigmatization in socially-mixed neighborhoods: A comparison of global-north and global-south problems. En P. Watt \& P. Smets (Eds.), Urban Renewal and Social Housing: A CrossNational Perspective. Bingley, UK: Emerald Books.

Salcedo, R. (2008). Reflexiones en torno a los guetos urbanos. Michel de Certau y la relación disciplina/anti-disciplina. Bifurcaciones, Revista de Estudios Culturales Urbanos, 7. Recuperado de http://www. bifurcaciones.cl/007/DeCerteau.htm

Servicio Hidrográfico y Oceanográfico de la Armada de Chile, SHOA. (2011). Plano actualizado año 2011.

Schlack, E. y Turnbull, N. (2009). La colonización de barrios céntricos por artistas. Revista 180, 24, 02-05. Recuperado de https://es.scribd.com/document/139678325/revista-180$\underline{24}$

Solimano, J. (2009). Millonario acuerdo por expropiación en Las Cabras. La Estrella de Iquique. Recuperado de http://www.estrellaiquique.cl/prontus4_nots/site/artic/20090422/pags/20090422001014. $\underline{\text { html }}$

Smith, N. (1996). La nueva frontera urbana; ciudad revanchista y gentrificación. Madrid: Traficantes de sueños.

Wacquant, L. (2001). Parias urbanos: marginalidad en la ciudad a comienzos del milenio. Buenos Aires: Manantial.

Wacquant, L. (2007). Los condenados de la ciudad. Gueto, periferias y Estado. Buenos Aires: Editorial Siglo XXI.

Wacquant, L., Slater, T., y Pereira, V. (2014). Estigmatización territorial en acción. Revista INVI, 29(82), 219-240. https://doi.org/10.4067/s0718-83582014000300008 